\title{
Research on Location of Power Grid Supplies Distribution Center based on Baumol-Wolfe Model
}

\author{
Yan-fu Zhang \\ School of Economics and Management, North China Electric Power University, Beijing, China
}

\begin{abstract}
Power grid supplies distribution center is an important node in grid logistics system. Distribution center position is appropriate or not directly related to the efficiency of power supply and logistics cost. Baumol-Wolf mode is established with minimizing total cost, which can provide a convenient and effective algorithm for the localization of the power grid supplies distribution center. Finally, an example is presented to illustrate the application of the model.

Index Terms - power grid supplies distribution center; location selection; Baumol-Wolf mode.

\section{Introduction}

Logistics network is an operation system which is composed of logistics nodes and the transport line. Logistics node in the network directly determines the whole logistics system operating costs and efficiency. With the rapid development of power grid construction, power grid operation and emergency rescue mission becomes more and more difficult [1]. How to improve the timeliness of supplies has become primary problem in face of power grid enterprises. Grid supplies distribution center as an important node in grid logistics system, its status and role has been highlighted. Therefore, to research on the location problem of grid supplies distribution center is helpful to improve the efficiency of the power supply, reduce the cost of storage and delivery for power grid enterprises.
\end{abstract}

\section{Literature Review}

This issue has been studied for many years in the world and a lot of achievements have been achieved by scholars at home and abroad. Aikens put forward 9 basic forms of location model which includes linear programming, 0-1 integer programming and dynamic programming [2]; Geoffrion and Grave studied on the location problem of distribution center which stores a variety of products, and proposed targeted solutions [3]. J.Korpel and A.Lehmusvaar researched on the distribution logistics network by applying analytic hierarchy process and mixed integer programming model [4]. Linda k. Nozick and Mark A. Turnquis take various factors into consideration like facility's fixed cost, transportation cost, inventory cost and so on. They finally proposed a location model of modern distribution center [5]. For power grid supplies distribution center, the research in this field is less. Ting $\mathrm{Li}$ set a double-layer location model according to the principle of "service" and "cost" [6]. Zhiren Zhang and Wanlong $\mathrm{Li}$ put forward a mixed-integer nonlinear programming to build grid materials warehouse location model [7]. Chunhui Liu et al. built CFLP model to solve the problems existing in the power grid supplies network, and utilized lingo software to obtain collection of distribution center [8]. Based on the traditional model, Guo Li established an optimization model of consisting with central warehouse and general warehouse, which are more suitable for the power industry, and the model's objective function is also the lowest cost [9].

Baumol-Wolfe model is used in resolving the location problem of distribution center in terms of transportation cost and its economy scale, which can provide a convenient effective algorithm for the localization of the power grid supplies distribution center.

\section{The Establishment of Baumol-Wolfe Model}

\section{A. Description of the Model}

Baumol-Wolfe model is applied in the situation for the localization of the distribution center between factories and customers. In this model, production capacity of factories and quantity demand of demand points have been known. Our goal is to find the appropriate number and location of distribution centers in a number of alternative addresses. In addition, we should also meet the supply and demand constraints to minimize the total cost (the sum of fixed cost and variable cost) [10].

\section{B. Model Building}

Firstly, the model assumes that $m$ is the number of factories, and factories dispatch products to customers through distribution centers. Similarly, $n$ is the number of customers. To be clear, production capacity of factories and demand of customers are known, and $s$ is the number of alternative address. Constraint conditions are as follow:

1) All customer requirements must be met

2) No more than each supply capacity of the factory

3) Total replenishment quantities are equal to total shipment quantity for each distribution center

The objective function:

$\min \sum_{j=1}^{s}\left(\sum_{i=1}^{m} C_{i j} X_{i j}+\sum_{k=1}^{n} D_{j k} Y_{j k}+W_{j} Z_{j}^{p}\right)+\sum_{j=1}^{s} V_{j} r\left(Z_{j}\right)$

Constraint condition:

$\sum_{j=1}^{s} \boldsymbol{X}_{i j}=\boldsymbol{A}_{i}$

$\sum_{j=1}^{s} Y_{i j}=\boldsymbol{B}_{k}$ 
$\sum_{i=1}^{m} X_{i j}=\sum_{k=1}^{n} Y_{i j}$

$X_{i j}>0$

$Y_{j k}>0$

Here, $i$ is factory $(i=1,2, \ldots, \mathrm{m}) ; j$ is distribution center $(j=1,2, \ldots, s) ; k$ is customer $(k=1,2, \ldots, n) ; A_{i}$ is the supply quantity of $i$ th factory; $B_{k}$ is the demand quantity of $k$ th customer; $C_{i j}$ is the transportation cost of unit from $i$ th factory to $j$ th distribution center; $D_{j k}$ is the transportation cost of unit from $j$ th distribution center to $k$ th customer; $Z_{j}$ is the turnover of $j$ th distribution center; $V_{j}$ is the fixed cost of the $j$ th distribution center; if $Z_{j}=0, r\left(Z_{j}\right)=0$, otherwise $r\left(Z_{j}\right)=1$; $W_{j}$ is the variable cost per unit of turnover of $j$ th distribution center (When we consider variable cost, introduce index $p$, meet the condition $0 \leq p \leq 1$, it will achieve scale-economy) [11]; $X_{i j}$ is the traffic volume from $i$ th factory to $j$ th distribution center; $Y_{j k}$ is the traffic volume from $j$ th distribution center to $k$ th customer; $U_{i k}$ is the turnover from $i$ th factory to $k$ th customer.

\section{Solution Method for Model}

Because the model is influenced by economies of scale, the objective function is non-linear. The model introduces index $\mathrm{p}(0 \leq p \leq 1)$, and use the iterative method to solve it.

The first step: solve the initial solution. At first, this model should figure out the all transportation cost of unit from factories to customers. Initial solution can be expressed as:

$C_{i l}^{0}=\min \left\{C_{i j}+D_{j k}\right\}$

Satisfy the constraint condition:

$\sum_{k=1}^{n} \boldsymbol{U}_{i k}=\boldsymbol{A}_{j}$

$\sum_{i=1}^{m} \boldsymbol{U}_{i k}=\boldsymbol{B}_{k}$

The second step: solve the second solution. Firstly, the model obtains the turnover of each distribution center.

$Z_{j}=\sum_{(i, k) \in G_{j}} U_{i k}$

Then the model sets a goal for minimizing the sum of the total transport cost and variable cost, and gets the second solution:

$C_{i k}^{1}=\min \left\{C_{i j}+D_{j k}+W_{i} P Z_{j}^{p-1}\right\}$

Similarly, satisfy the constraint condition: $\sum_{k=1}^{n} U_{i k}=A_{j}$

$\sum_{i=1}^{m} \boldsymbol{U}_{i k}=\boldsymbol{B}_{k}$

The third step: solve the optimal solution. This model repeats the method of second step, and compare twice $Z_{j}$ after solution. If the results are equal, the model can terminate the calculation. Finally, the solution is the optimal solution.

\section{Instance Analysis}

A power grid enterprise has two vendors $\left(A_{1}, A_{2}\right)$ and eight demand points $\left(B_{1}-B_{8}\right)$ in a certain region. Enterprise wants to build a certain number of power grid supplies distribution centers and confirms five alternative addresses $\left(\mathrm{D}_{1}-\mathrm{D}_{5}\right)$ by investigation. Concrete data are showed in TABLE I to TABLE III. The goal is to minimize the total cost of logistics for power grid enterprise.

TABLE I The Transportation Cost of Unit from Vendors to Alternative Addresses

\begin{tabular}{|c|c|c|c|c|c|c|}
\hline \multirow{2}{*}{$\begin{array}{l}\text { Alternative } \\
\text { addresses } \\
\text { Vendors }\end{array}$} & \multicolumn{5}{|c|}{$\begin{array}{c}\text { The transportation cost of unit from } \\
\text { vendors to alternative addresses }\end{array}$} & \multirow{2}{*}{ Supply } \\
\hline & $\mathrm{D}_{1}$ & $\mathrm{D}_{2}$ & $\mathrm{D}_{3}$ & $\mathrm{D}_{4}$ & $\mathrm{D}_{5}$ & \\
\hline $\mathrm{A}_{1}$ & 5 & 10 & 20 & 40 & 45 & 200 \\
\hline $\mathrm{A}_{2}$ & 25 & 13 & 7 & 15 & 17 & 400 \\
\hline
\end{tabular}

TABLE II The Transportation Cost of Unit from Distribution Centers to Demand Points

\begin{tabular}{|c|c|c|c|c|c|c|c|c|}
\hline \multirow{2}{*}{$\begin{array}{l}\text { Demand } \\
\text { points }\end{array}$} & \multicolumn{8}{|c|}{$\begin{array}{l}\text { The transportation cost of unit from alternative } \\
\text { addresses to demand points }\end{array}$} \\
\hline & $\mathrm{B}_{1}$ & $\mathrm{~B}_{2}$ & $\mathrm{~B}_{3}$ & $\mathrm{~B}_{4}$ & $\mathrm{~B}_{5}$ & $\mathrm{~B}_{6}$ & $\mathrm{~B}_{7}$ & $\mathrm{~B}_{8}$ \\
\hline $\mathrm{D}_{1}$ & 12 & 5 & 13 & 22 & 30 & 46 & 41 & 50 \\
\hline $\mathrm{D}_{2}$ & 50 & 13 & 5 & 10 & 17 & 33 & 27 & 37 \\
\hline $\mathrm{D}_{3}$ & 34 & 22 & 10 & 5 & 9 & 25 & 19 & 29 \\
\hline $\mathrm{D}_{4}$ & 58 & 46 & 33 & 25 & 16 & 10 & 9 & 9 \\
\hline $\mathrm{D}_{5}$ & 59 & 50 & 37 & 29 & 17 & 9 & 18 & 5 \\
\hline Demand & 40 & 60 & 160 & 80 & 120 & 60 & 40 & 40 \\
\hline
\end{tabular}

TABLE III The Variable Cost of Each Alternative Addresses $\left(W_{j} Z_{j}^{p}\right)$

\begin{tabular}{|c|c|c|c|c|c|}
\hline $\begin{array}{c}\text { Alternative } \\
\text { addresses }\end{array}$ & $\mathrm{D}_{1}$ & $\mathrm{D}_{2}$ & $\mathrm{D}_{3}$ & $\mathrm{D}_{4}$ & $\mathrm{D}_{5}$ \\
\hline $\begin{array}{c}\text { Variable } \\
\text { cost }\end{array}$ & $300 Z_{1}^{p}$ & $600 Z_{2}^{p}$ & $500 Z_{3}^{p}$ & $200 Z_{4}^{p}$ & $200 Z_{5}^{p}$ \\
\hline
\end{tabular}

\section{A. Solve the Initial Solution}

Above all, the model can obtain the minimum transportation cost $C_{i k}^{0}=\min \left\{C_{i j}+D_{j k}\right\}$. The results are showed in TABLE IV. 
TABLE IV The Minimum Transportation Cost

\begin{tabular}{|c|c|c|c|c|c|c|c|c|}
\hline \multirow{2}{*}{$\begin{array}{c}\text { Deman } \\
\text { points }\end{array}$} & \multicolumn{7}{|c|}{ The minimum transportation cost } \\
\cline { 2 - 9 } Vendors & $\mathrm{B}_{1}$ & $\mathrm{~B}_{2}$ & $\mathrm{~B}_{3}$ & $\mathrm{~B}_{4}$ & $\mathrm{~B}_{5}$ & $\mathrm{~B}_{6}$ & $\mathrm{~B}_{7}$ & $\mathrm{~B}_{8}$ \\
\hline \multirow{2}{*}{$\mathrm{A}_{1}$} & 17 & 10 & 15 & 20 & 27 & 43 & 37 & 47 \\
& $\mathrm{D}_{1}$ & $\mathrm{D}_{1}$ & $\mathrm{D}_{2}$ & $\mathrm{D}_{2}$ & $\mathrm{D}_{2}$ & $\mathrm{D}_{2}$ & $\mathrm{D}_{2}$ & $\mathrm{D}_{2}$ \\
\hline \multirow{2}{*}{$\mathrm{A}_{2}$} & 37 & 26 & 17 & 12 & 16 & 20 & 24 & 22 \\
& $\mathrm{D}_{1}$ & $\mathrm{D}_{2}$ & $\mathrm{D}_{3}$ & $\mathrm{D}_{3}$ & $\mathrm{D}_{3}$ & $\mathrm{D}_{4}$ & $\mathrm{D}_{4}$ & $\mathrm{D}_{5}$ \\
\hline
\end{tabular}

According to the data above, the model can get the initial solution. The results are showed in TABLE V.

TABLE V The Initial Solution

\begin{tabular}{|c|c|c|c|c|c|c|c|c|c|}
\hline Deman & \multicolumn{8}{|c|}{ The initial solution } & \multirow[t]{2}{*}{ Supply } \\
\hline Vendors & $\mathrm{B}_{1}$ & $\mathrm{~B}_{2}$ & $\mathrm{~B}_{3}$ & $\mathrm{~B}_{4}$ & $\mathrm{~B}_{5}$ & $\mathrm{~B}_{6}$ & $\mathrm{~B}_{7}$ & $\mathrm{~B}_{8}$ & \\
\hline$A_{1}$ & $\begin{array}{l}40 \\
D_{1}\end{array}$ & $\begin{array}{l}60 \\
D_{1}\end{array}$ & $\begin{array}{c}100 \\
\mathrm{D}_{2}\end{array}$ & & & & & & 200 \\
\hline $\mathrm{A}_{2}$ & & & $\begin{array}{l}60 \\
D_{3}\end{array}$ & $\begin{array}{l}80 \\
\mathrm{D}_{3}\end{array}$ & $\begin{array}{c}120 \\
\mathrm{D}_{3}\end{array}$ & $\begin{array}{l}60 \\
D_{4}\end{array}$ & $\begin{array}{l}40 \\
D_{4}\end{array}$ & $\begin{array}{l}40 \\
D_{5}\end{array}$ & 400 \\
\hline Demand & 40 & 60 & 160 & 80 & 120 & 60 & 40 & 40 & 600 \\
\hline
\end{tabular}

The initial solution only consider transport cost, but do not take the cost of distribution center into consideration, which include the fixed cost and variable cost. So the model thinks more about the influence of variable cost to making a comparison.

\section{B. Solve the Second Solution}

According to the initial solution, the model can obtain the turnover of each distribution center and the variable cost of unit in average (the variable cost of unit in average $=W_{j} P Z_{j}^{p} / Z_{j}$, set $p=0.5)$. The data are showed in TABLE VI.

TABLE VI The Turnover and The Variable Cost of Unit in Average

\begin{tabular}{|c|c|c|c|c|c|}
\hline Alternative addresses & $\mathrm{D}_{1}$ & $\mathrm{D}_{2}$ & $\mathrm{D}_{3}$ & $\mathrm{D}_{4}$ & $\mathrm{D}_{5}$ \\
\hline Turnover & 100 & 100 & 260 & 100 & 40 \\
\hline The variable cost of unit in average & 15 & 30 & 15.5 & 10 & 15.8 \\
\hline
\end{tabular}

The variable cost of unit in average plus the corresponding minimum transportation cost, and the model can get the minimum comprehensive cost. The results are showed in TABLE VII.

TABLE VII The Minimum Comprehensive Cost

\begin{tabular}{|c|c|c|c|c|c|c|c|c|}
\hline $\begin{array}{r}\text { Deman } \\
\text { peints }\end{array}$ & \multicolumn{7}{|c|}{ The minimum comprehensive cost } \\
\cline { 2 - 10 } Vendors & $\mathrm{B}_{1}$ & $\mathrm{~B}_{2}$ & $\mathrm{~B}_{3}$ & $\mathrm{~B}_{4}$ & $\mathrm{~B}_{5}$ & $\mathrm{~B}_{6}$ & $\mathrm{~B}_{7}$ & $\mathrm{~B}_{8}$ \\
\hline \multirow{2}{*}{$\mathrm{A}_{1}$} & 32 & 25 & 33 & 40.5 & 44.5 & 55 & 54.5 & 59 \\
& $\mathrm{D}_{1}$ & $\mathrm{D}_{1}$ & $\mathrm{D}_{1}$ & $\mathrm{D}_{3}$ & $\mathrm{D}_{3}$ & $\mathrm{D}_{4}$ & $\mathrm{D}_{3}$ & $\mathrm{D}_{4}$ \\
\hline \multirow{2}{*}{$\mathrm{A}_{2}$} & 52 & 44.5 & 32.5 & 27.5 & 31.5 & 30 & 34 & 34 \\
& $\mathrm{D}_{1}$ & $\mathrm{D}_{3}$ & $\mathrm{D}_{3}$ & $\mathrm{D}_{3}$ & $\mathrm{D}_{3}$ & $\mathrm{D}_{4}$ & $\mathrm{D}_{4}$ & $\mathrm{D}_{4}$ \\
\hline
\end{tabular}

The model chooses the minimum value of the sum of the variable cost and transport cost, and then solves the transportation problem. Finally, get the second solution. The results are showed in TABLE VIII.
TABLE VIII The Second Solution

\begin{tabular}{|c|c|c|c|c|c|c|c|c|c|}
\hline \multirow{2}{*}{$\begin{array}{c}\text { Demand } \\
\text { Roints }\end{array}$} & \multicolumn{7}{|c|}{ The second solution } & \multirow{2}{*}{ Supply } \\
\cline { 3 - 10 } Vendors & $\mathrm{B}_{1}$ & $\mathrm{~B}_{2}$ & $\mathrm{~B}_{3}$ & $\mathrm{~B}_{4}$ & $\mathrm{~B}_{5}$ & $\mathrm{~B}_{6}$ & $\mathrm{~B}_{7}$ & $\mathrm{~B}_{8}$ & \\
\hline \multirow{2}{*}{$\mathrm{A}_{1}$} & 40 & 60 & 100 & & & & & & 200 \\
& $\mathrm{D}_{1}$ & $\mathrm{D}_{1}$ & $\mathrm{D}_{1}$ & & & & & & 200 \\
\hline \multirow{2}{*}{$\mathrm{A}_{2}$} & & & 60 & 80 & 120 & 60 & 40 & 40 & \multirow{2}{*}{400} \\
\hline Demand & 40 & 60 & 160 & 80 & 120 & 60 & 40 & 40 & 600 \\
\hline
\end{tabular}

\section{Solve the Optimal Solution}

In a similar way, the model can get the turnover, the variable cost of unit in average and the minimum comprehensive cost of the third step. Because the turnover of alternative addresses $D_{2}$ and $D_{5}$ is zero, the model assumes their variable cost of unit in average is infinity so that we can cancel the two alternative distribution centers. The data are showed in TABLE IX to TABLE XI.

TABLE IX The Twice Turnover and The Variable Cost of Unit in Average

\begin{tabular}{|c|c|c|c|c|c|}
\hline Alternative addresses & $\mathrm{D}_{1}$ & $\mathrm{D}_{2}$ & $\mathrm{D}_{3}$ & $\mathrm{D}_{4}$ & $\mathrm{D}_{5}$ \\
\hline Turnover & 200 & 0 & 260 & 140 & 0 \\
\hline The variable cost of unit in average & 10.6 & $\infty$ & 15.5 & 8.5 & $\infty$ \\
\hline
\end{tabular}

TABLE X The Minimum Comprehensive Cost

\begin{tabular}{|c|c|c|c|c|c|c|c|c|}
\hline Demand & \multicolumn{7}{|c|}{ The minimum comprehensive cost } \\
\cline { 2 - 9 } Vendors & $\mathrm{B}_{1}$ & $\mathrm{~B}_{2}$ & $\mathrm{~B}_{3}$ & $\mathrm{~B}_{4}$ & $\mathrm{~B}_{5}$ & $\mathrm{~B}_{6}$ & $\mathrm{~B}_{7}$ & $\mathrm{~B}_{8}$ \\
\hline \multirow{2}{*}{$\mathrm{A}_{1}$} & 27.6 & 20.6 & 28.6 & 37.6 & 45.6 & 53.5 & 54.5 & 57.5 \\
& $\mathrm{D}_{1}$ & $\mathrm{D}_{1}$ & $\mathrm{D}_{1}$ & $\mathrm{D}_{1}$ & $\mathrm{D}_{1}$ & $\mathrm{D}_{4}$ & $\mathrm{D}_{3}$ & $\mathrm{D}_{4}$ \\
\hline \multirow{2}{*}{$\mathrm{A}_{2}$} & 47.6 & 40.6 & 32.5 & 27.5 & 31.5 & 28.5 & 32.5 & 32.5 \\
& $\mathrm{D}_{1}$ & $\mathrm{D}_{1}$ & $\mathrm{D}_{3}$ & $\mathrm{D}_{3}$ & $\mathrm{D}_{3}$ & $\mathrm{D}_{4}$ & $\mathrm{D}_{4}$ & $\mathrm{D}_{4}$ \\
\hline
\end{tabular}

TABLE XI The Third Solution (The Optimal Solution)

\begin{tabular}{|c|c|c|c|c|c|c|c|c|c|}
\hline \multirow{2}{*}{$\begin{array}{l}\text { Demand } \\
\text { points }\end{array}$} & \multicolumn{7}{|c|}{ The third solution } & \multirow{2}{*}{ Supply } \\
\cline { 2 - 10 } & $\mathrm{B}_{1}$ & $\mathrm{~B}_{2}$ & $\mathrm{~B}_{3}$ & $\mathrm{~B}_{4}$ & $\mathrm{~B}_{5}$ & $\mathrm{~B}_{6}$ & $\mathrm{~B}_{7}$ & $\mathrm{~B}_{8}$ & \\
\hline $\mathrm{A}_{1}$ & 40 & 60 & 100 & & & & & & 2 \\
& $\mathrm{D}_{1}$ & $\mathrm{D}_{1}$ & $\mathrm{D}_{1}$ & & & & & & \\
\hline \multirow{2}{*}{$\mathrm{A}_{2}$} & & & 60 & 80 & 120 & 60 & 40 & 40 & 400 \\
& & & $\mathrm{D}_{3}$ & $\mathrm{D}_{3}$ & $\mathrm{D}_{3}$ & $\mathrm{D}_{4}$ & $\mathrm{D}_{4}$ & $\mathrm{D}_{4}$ & \\
\hline Demand & 40 & 60 & 160 & 80 & 120 & 60 & 40 & 40 & 600 \\
\hline
\end{tabular}

Because the second solution is equal to the third solution, the third solution is the optimal solution. The model can get the optimal solution from TABLE XI that the power grid company has better choose $D_{1}, D_{3}, D_{4}$ as power grid supplies distribution center.

\section{Conclusion}

The reasonable location of the facility is the key link to building the whole system, and it often determines the network model, structure and efficiency of the system [12]. For power grid enterprises, a better location can not only reduce building and operating cost effectively, save transportation cost and time, and but also can improve the efficiency of the power supply, ensure the safe operation of the power grid. BaumolWolfe Model is applied to the research on the localization of 
the power grid supplies distribution center. Finally, in an example, it proves the feasibility and applicability of this model.

\section{References}

[1] Zheng, B. S. et al, Supplies Intensive Management of State Grid, Beijing: China Electric Power Press, 2012.

[2] Aikens C.H., Facility location models for distribution planning, European Journal of Operational Research, vol. 22, pp. 263-279, 1985

[3] Geoffrion A.M., Graves G.M., Multi-commodity distribution system design by benders decomposition, Management Science, vol. 20, pp. 822-844, 1974.

[4] Jukka K., Antti L., A customer oriented approach to warehouse network evaluation and design, International Journal of Production Economics, vol. 59, pp. 135-146, 1999.

[5] Linda K.N., Mark A.T., Inventory, transportation, service quality and the location of distribution centers. European Journal of Operational Research, vol. 129, pp. 362-37, 2001.
[6] Li, T., Power grid materials warehouse scale forecast and location planning. Unpublished master dissertation, Shandong University, Shandong, China, 2011.

[7] Zhang, Z. R and Li, W. L., Research on power grid supplies the centralized storage network build strategy of Zhejiang province, Modern Business, pp. 19-20, 2012.

[8] Liu, C. H., et al, Material storage network layout optimization of power grid enterprises based on CFLP model. Economic Research Guide, vol. 31, pp. 20-21, 2014.

[9] Li, G., The study on optimization for warehousing and distribution networks in electric power industry. Unpublished master dissertation. Huazhong University of Science and Technology, Wuhan, China, 2011.

[10] Li, Y. Q., Logistics System Planning, Shanghai: Tongji University Press, 2004.

[11] Yu, Z. X., Study on location of retail chains' distribution center based on Baumol-Wolfe model. Manager' Journal, vol. 11, pp. 391-393, 2011.

[12] Qiao, J. Y., Zhu, S. J., and Wang, C. R., Study on Method of Facilities Location Allocation. Logistics Technology, vol. 1, pp. 22-25, 2015. 